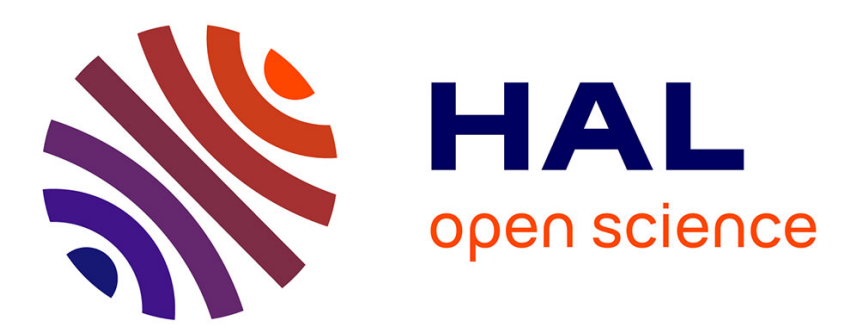

\title{
Do female researchers face a glass ceiling in France? A hazard model of promotions
}

\author{
Sabatier Mareva, Carrere Myriam
}

\section{To cite this version:}

Sabatier Mareva, Carrere Myriam. Do female researchers face a glass ceiling in France? A hazard model of promotions. Applied Economics, 2010, 42 (16), pp.2053-2062. 10.1080/00036840701765338 . hal-00605543

\section{HAL Id: hal-00605543 \\ https://hal.science/hal-00605543}

Submitted on 2 Jul 2011

HAL is a multi-disciplinary open access archive for the deposit and dissemination of scientific research documents, whether they are published or not. The documents may come from teaching and research institutions in France or abroad, or from public or private research centers.
L'archive ouverte pluridisciplinaire HAL, est destinée au dépôt et à la diffusion de documents scientifiques de niveau recherche, publiés ou non, émanant des établissements d'enseignement et de recherche français ou étrangers, des laboratoires publics ou privés. 


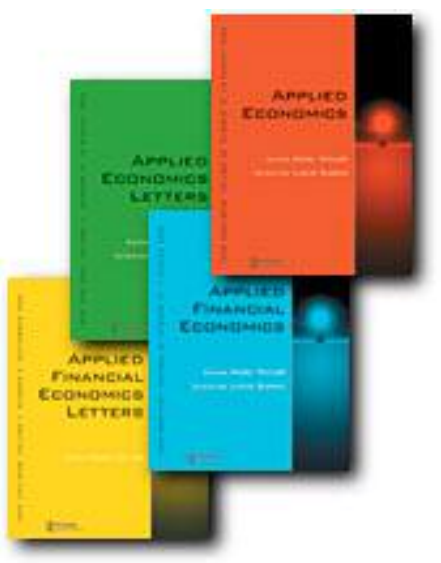

Do female researchers face a glass ceiling in France ? A hazard model of promotions

\begin{tabular}{|r|l|}
\hline Journal: & Applied Economics \\
\hline Manuscript ID: & APE-06-0523.R1 \\
\hline Journal Selection: & Applied Economics \\
\hline Date Submitted by the \\
Author: & 28-May-2007 \\
\hline JEL Code: & $\begin{array}{l}\text { Labor and Demographic Economics, C41 - Duration Analysis \&lt; C4 } \\
\text { - Econometric and Statistical Methods: Special Topics \&lt; C - } \\
\text { Mathematical and Quantitative Methods }\end{array}$ \\
\hline Keywords: & $\begin{array}{l}\text { Mareva, SABATIER; IMUS, Département Economie-Finance } \\
\text { Myriam, Carrere; INRA, UMR GAEL }\end{array}$ \\
\hline \multicolumn{2}{|r}{} \\
\hline
\end{tabular}

\section{s) ScholarONE" \\ Manuscript Central}




\title{
Do Female Researchers Face a Glass Ceiling in France? A Hazard Model of Promotions
}

\author{
Mareva Sabatier*, Myriam Carrère ${ }^{\circ 1}$ \\ * IREGE, Université de Savoie, France \\ mareva.sabatier@univ-savoie.fr \\ ${ }^{\circ}$ UMR GAEL, INRA Grenoble, France \\ myriam.carrere@grenoble.inra.fr
}

\section{Abstract:}

Our article aims at testing whether French female researchers face a glass ceiling, an invisible barrier to promotion. Using an original database from the National Institute for Agricultural Research, we estimate duration models of promotions. This methodology allows us to take into account censored observations and unobserved heterogeneity. Our results exhibit a significant gender effect, which does not contradict the glass ceiling hypothesis. Moreover, gender does not have a uniform effect. It interacts with other variables so that there exist factors that accelerate promotion, while others tend to slow it down.

Keywords: Promotion, Glass Ceiling, Gender Gap Code JEL: J16, C41

\footnotetext{
1 Corresponding author: Mareva Sabatier, UFR ATE, 4 chemin de Bellevue, BP 806, 74016 Annecy Cedex, France. tel.: 00-33-4-50-09-24-59; fax: 00-33-4-50-09-24-10 ; e-mail: mareva.sabatier@univ-savoie.fr
} 


\section{$\underline{\text { I- Introduction }}$}

Whatever the profession (Albrecht, et al., 2003; Joy, 1998; Spurr and Sueyoshi, 1994), the literature provides a large amount of evidence on the underrepresentation of women in senior positions. This suggests that women face a glass ceiling, which limits their promotion. Although academia attracts more and more women, Benjamin (1999) notes that this sector does not seem to escape the glass ceiling phenomenon. The ETAN Report (2000) states that, in all OECD countries, the proportion of females decreases further up the rank ladder. On average, three times more women and twice as many women are founded in the "assistant" (30.5\% of women) and "lecturer" positions (20.5\% of women) than in the "full professor" grade (10.4\%).

These statistics seem then to be consistent with the presence of a glass ceiling. But, observed gender differences among academics could be caused by gender disparities in different activities. For example, Schneider (1998) notes that women are found more in pedagogical activities. This could explain why they tend to publish less and why they are less likely to be promoted. So, in order to establish the existence of a glass ceiling in academia, other factors that affect careers must be taken into account. Only an econometric analysis will allow this ceteris paribus analysis.

However, microeconometric studies are relatively scarce and most of them have focused on wages. On the basis of Mincer equations, studies generally find significant wage gaps between men and women, even after controlling for individual characteristics, publication scores, department characteristics and so forth. Using American data from the Survey of Doctorate Recipients (SDR), 
Ginther and Hayes (1999) calculate the gender gap to be 9\% in Human Sciences for men. For Ward (2001), women in Scottish academia earn 26\% less than their male counterparts. Although these results do not refute the glass ceiling hypothesis, cracks do appear. First, the gender wage gap has decreased since the 1970's (Ransom and Megdal, 1993). Second, estimated wage gaps are mainly caused by gender differences in observable heterogeneity. Using the Oaxaca decomposition, Ward (2001) shows that only three percentage points of the $26 \%$ estimated can be attributed to discrimination. Ginther and Hayes (2003) confirm this result and demonstrate that gender rank differentials mainly explain gender wage gaps. This suggests that wages follow the rank ladder.

Since then, the literature has focused on the promotion process. Ginther and Hayes (2003) estimate the promotion probability using univariate probit models. They conclude that women in Human Sciences are significantly less likely to be promoted to tenured positions, ceteris paribus: the estimated gap is about $8 \%$. Mixon and Trevino (2005) confirm the female discrimination for economists in the US South. This result remains true when the dynamic process of promotion is taken into account. Using a random-effects probit model, Mc Dowell et al. (1999) conclude that the "average women" is $36 \%$ less likely to be promoted to the "assistant professor" rank and 9\% less likely to be promoted to the "full professor" rank. In the same way, Kahn (1993) finds that, in Economics, risk ratios for women to become tenured are about two-third of the male rate. Ginther and Hayes (2003) find similar results in Humanities. The estimated gender gap in promotion rates is large: women are $25 \%$ less likely to be promoted, ceteris paribus. 
Finally, the empirical literature does not refute the hypothesis that women are less likely to gain access senior position. This seems to illustrate the existence of a glass ceiling for academics, whatever the discipline. But, existing results are based on American or British data, countries which have very similar academic systems. It could be argued that gender gaps result from a particular organization of academia which is unfair to females. It would be useful to test the glass ceiling hypothesis in another type of organization and the French academic system provides an interesting alternative framework. Indeed, French academia has a number of specific features that make it quite different from the USA or Great Britain (see Ginther (2001) and Euwals and Ward (2000) for a detailed description of each academic system).

First, in contrast to other countries, the academic sector is two-headed and is comprised of universities and national research laboratories. Each institution is independent and has its own working rules. For example, researchers working in one of the national research institutes have no teaching duties, unlike those working in universities.

Second, in the USA or Great Britain, academic careers depend on tenure rules. After their PhD., young researchers are hired as assistant professors on a fixed term contract. Afterwards, for those who gain access to it, life-long employment (as Full Professor) is proposed. Promotion criteria include scientific achievements, such as the number of publications and their quality. French academia is organised quite differently. The key difference is that the life-time contract begins soon after hiring, whatever the institution (universities or national research 
laboratories) or disciplines. While hiring depends on the quality of research performed during the PhD., researchers become tenured civil servants after only 12 months probation and this occurs almost automatically. Civil servant status implies a life-long job and, for a given rank, a fixed wage scale. Two main ranks exist in each research institution: assistant professor (or its equivalent in national laboratories: the researcher rank) and full professor (or the senior researcher rank). For a given status, wages are fixed by a national collective agreement and are the same for all universities or research laboratories. Finally, no difference in terms of wages for a given level will be observed.

In France, the objective of seeking promotion is not to get tenure (since this is automatic). Higher wages and greater responsibilities (such as being a PhD. advisor or managing a team of researchers) motivate researchers or assistant professors to become senior researchers or full professors. As in other countries, promotion to the senior rank depends on scientific achievements, which are examined by promotion committees.

Another difference is that all disciplines in French academia are organized according to this general framework: general hiring and career rules are common. As stressed in the stylized facts, if the promotion process is studied, one finds that large gender differences exist. This suggests that, in spite of the different organization of the academic sector, French female researchers are also underrepresented in senior ranks, and this is a sign of a glass ceiling. 
The aim of this article is to test whether this hypothesis can be refuted or not on by studying promotion paths. As in the previous literature, we will take account of both observed heterogeneity, such as individual attributes and scientific achievements, which can explain promotions gaps and also unobserved heterogeneity, which is often neglected. As career paths in French academia can only be described by rank evolution, the gender effect is evaluated on the hazard of becoming a "Senior Researcher".

We do face one major difficulty though since, in France, no data set is generally available to study academic careers. In section two we explain how we have constructed a panel data set for researchers' careers. This data set allows us to follow a group of biologists, working at the National Institute for Agricultural Research, called INRA, one of the national research institutes in France. Focusing both on life scientists in only one institute will enable us to test the glass ceiling hypothesis with homogenous data (one discipline in one institute) and to provide the first study of this phenomenon for France.

\section{II- The Data}

As no dataset exists to describe the career paths of researchers in France, we have constructed one, based on administrative files from the National Institute for Agricultural Research (INRA). Founded in 1946, this institute aims at developing scientific knowledge, particularly in the fields of agriculture, food and the environment. In 2002, INRA had 260 research departments and employed about 1,800 researchers, $37 \%$ of whom are female. As in other national laboratories, these researchers are grouped in two ranks. The lowest rank comprises 
Researchers (R) and the higher Senior Researchers (SR), and 35\% of the INRA researchers are at the senior rank.

As in other national research institutes, gender parity is nearly established in the "Researcher" rank, but, women are under-represented in the senior rank: 5.5\% of researchers are female senior researchers. Furthermore, at INRA, the situation for female researchers is worse than in other public research institutes or universities. In Table 1, it can be seen that the share of senior researchers among women is ten percentage points lower at INRA than in other public institutes.

\section{[INSERT TABLE 1]}

At INRA, the traditional career path is to begin at the Researcher rank and later possibly to accede to the Senior rank ${ }^{2}$. We focus on this particular promotion path. Promotion to the "Senior Researcher" rank occurs mainly through an internal competitive process. The promotion process is formal: available positions are published on INRA's website or in newspapers. Applicants have to submit their $\mathrm{CV}$, an outline of their previous research activities (mainly realized during their tenure at INRA) and of their future projects. Promotion committees, composed of researchers from INRA and other institutes or universities, examine applications and make a first selection, on the basis on scientific achievements. Selected researchers are then interviewed, ranked and eventually promoted. In the dataset, we can observe the whole of an individual's career at INRA and how long individuals stay in the Researcher grade before reaching the Senior

\footnotetext{
${ }^{2}$ A small number of direct entries at the senior rank are observed and this very recently. This type of career cannot be regarded as a promotion at INRA and is not analysed in this study.
} 
Researcher rank. In section three, we are interested in testing whether gender produces a significant effect on this duration, which is sometimes right-censored.

Among researchers at INRA, we have decided to focus on researchers in biology, which is the main discipline at INRA. Our sample contains 583 researchers and in order to describe their career paths, we match two administrative data sets. The first describes the length of time spent in each known rank. The second data set gives us access to the activity report that each researcher supplies for his or her annual evaluation. These data are collected from the time the researcher begins to work at INRA to the time of their promotion to the SR position or to the end of 2002, if they are still in the researcher rank at this time. It must be noted that most of the observed researchers have begun their career at INRA: they do not have prior experience.

We observe several cohorts of researchers. A dummy variable, $\mathrm{COH} 1$ (being hired at INRA before 1980), is created to capture potential cohorts effects, as in Ransom and Megdal (1993). These effects could reflect changes in the promotion process. Indeed, as in the French academic sector as a whole, recent recruitments and promotions seem to be more competitive than in the early eighties.

We also have information on several individual attributes. For example, we know if researchers have graduated from a Top University (TOP_UNIV). These universities, the "Grandes Ecoles", are considered, in France, as attracting the best students. We also know whether a researcher can act as a PhD. Supervisor (HDR). 
In France, a particular diploma, the "HDR"3, is required to be able to supervise PhDs and our data indicates whether a researcher has this diploma. These two variables, TOP_UNIV and HDR, then could act as signal of a higher human capital and play a role in the promotion process.

Our data also contain information on the researchers' mobility. This mobility could result from a postdoctoral fellowship (POSTDOC) or a visiting professorship or sabbatical abroad, after being hired at INRA (MOB). Mobility is often viewed as an opportunity for acquiring new competencies and for networking. Developed networks through the scientific community provide higher opportunities for collaborations and could increase scientific achievements. Mobility could then boost promotions.

In contrast to other data sets used in the literature, our sample contains information on all aspects of the researchers' work. We know each research's publication record and, in order to complement this information, we add a third data set provided by the Science Citation Index (SCI) which gives us, for each publication, its impact factor (according to the journal index quality) ${ }^{4}$. Using these two variables, we construct a publishing score (articles published weighted by the journal quality), reflecting publishing productivity (PUB_SCORE). Following Mc Dowell et al. (2001), this mixed indicator is preferred to a simple quantitative measure of publications, which ignores the visibility or reputation of the scientific work. In addition there is information on the degree of implication in scientific projects (as participant, NPROJECT, or coordinator, NPROJ_C) and in

\footnotetext{
3 "HDR" diploma or "Habilitation" consists in writing a document which outlines the contribution to science. As the PhD., this document is defended in front of a jury.

${ }^{4}$ It must be noted that the impact factor is complete for all publications from the early 80 's, but it could be more imprecise for earlier publications. This must then be taken into account in the econometric results and comments.
} 
administrative activities. These activities comprise managing a research team or a department (BOSS) or networking activities such as professional affiliations (NETW) or being involved in strategic committees, recruitment or promotions committees (COMMIT). All these attributes then allow us to have more precise information on scientific achievements and their visibility, which are a main pillar of the promotion criteria.

The richness of our data set may have a negative counterpart: scientific achievements might be endogenous. For example, the most highly motivated researchers could be the ones who have the most important activities and who are the most likely to be promoted. This type of mechanism probably underlies the career process. But, to be identified, such a process needs valid instruments. Unfortunately, our dataset is not informative enough to allow us to test both determinants of scientific achievements and those of duration to promotion.

Furthermore, our administrative data set does not gather information on personal characteristics, such as marital status and number of children or on research departments' activities. However, previous studies have found these variables to have a significant effect on the promotion process. Neglecting these attributes could generate an omitted variable bias and this point will be discussed in the next section.

Table 2 provides descriptive statistics on the overall sample and on sub-samples based on gender or/and rank. Among the 583 individuals in the sample, 37.4\% are female and $32.4 \%$ are Senior Researchers. However, only $5.7 \%$ of women are in senior positions. These figures are very close to the general situation at INRA (i.e. for all disciplines): women are under-represented in the highest rank. Table 2 also 
shows that there are large differences in the average researcher's profile according to gender and rank. First, large differences exist between individuals who have been promoted to the SR rank (column SR) and those still in R rank. $17.4 \%$ of senior researchers are women (20 percentage points less than the number of women in the sample). Those promoted have been recruited earlier at INRA, on average, in 1976 (instead 1985 in the full sample). They also have lower publishing scores, and are more involved in administrative activities. Women tend to have been recruited more recently than men at INRA. Females also have higher publishing score than male and have fewer administrative activities.

\section{[INSERT TABLE 2]}

\section{III- Modelling the determinants of promotion duration}

The descriptive evidence clearly indicates that women are under-represented in "Senior Researcher" position at INRA. Our aim is to test whether this gender differential remains after controlling for observed and unobserved heterogeneity. Instead of estimating the probability of being promoted, we focus attention on the hazard rate, denoted $\lambda_{i}(t)$. This hazard rate can be written as follows:

$$
\lambda_{i}(t)=\frac{p(t \leq T<t+d t / T \geq t)}{p(T \geq t)}=\frac{f(t)}{S(t)}
$$

where $T$ is the length of time passed in the "Researcher" rank, $f(t)$ is the density distribution and $S(t)$ the survival function. 
Using the model of Mc Dowell et al. (1999), $\lambda$ can be viewed as the probability at time $t$ that an individual's productivity exceeds the department productivity threshold (probability of being promoted), given that this productivity is lower at least until $t$ (probability of being not promoted until $t$ ). As both individual productivity and the department's norm are latent variables, $\lambda$ denotes the probability of becoming senior researcher, given that no promotion occurs before $t$. Estimating this hazard rate involves the use of duration models (Lancaster, 1990). This methodology allows us to take into account that $67.6 \%$ of the individuals are still in the "Researcher" rank at the sample date, that is more than two thirds of observed durations are right-censored. We estimate a parametric model (with an accelerated failure-time form) which allows one to control for both observed and unobserved explanatory factors. Kaplan-Meier estimates have shown that hazard rates are non-monotonic, and therefore a log-normal distribution ${ }^{5}$ is applied.

In our parametric specification, the hazard rate, $\lambda_{i}$, is assumed to depend on three arguments: a vector of observable characteristics $X_{i}$, an individual specific effect, $v_{i}$ and an error term $\varepsilon_{i}$.

The $X$ vector includes gender, mobility characteristics, publishing score, investment in projects and administrative activities. The $v_{i}$ term is added to capture individual unobserved heterogeneity. Using panel models, Mc Dowell et al. (2001) have pointed out that neglecting unobserved heterogeneity could cause endogeneity bias and lead to spurious results. We use administrative files, in

\footnotetext{
${ }^{5}$ Various specifications for distributions of durations (log-logistic, weibull, ...) were tested. The results are not affected by this
} choice. 
which several attributes are lacking, such as the number of children, the marital status or the characteristics of the research departments. As noted earlier, studies have found that these variables have significant effects. Omitting these variables could then increase the risk of endogeneity bias. We are able to overcome this difficulty by modelling $v_{i}$ term with a gamma distribution $\left(\Gamma\left(v_{i}\right)\right)$ with unit mean and variance $\theta$.

The survival function, denoted $S(t)$, can then be written as follows:

$$
S\left(t_{i}\right)=\int_{v_{i}} S\left(t_{i} \mid v_{i}\right) f\left(v_{i}\right) d v_{i}
$$

with:

- $S\left(t_{i} / v_{i}\right)=\Phi\left[-\sigma \ln \left(\lambda_{i} t_{i}\right)\right]$

where $\lambda_{i}=e^{-\beta^{\prime} X_{i}}, t_{i}$ the promotion duration and $\Phi$ the cumulative distribution function for the standard normal distribution, and:

- $f\left(v_{i}\right)=\frac{k^{k}}{\Gamma(k)} e^{-k v_{i}} v_{i}^{k-1}$, where $k=\frac{1}{\theta}$

From this general specification, three different models are estimated. Model 1 imposes the restriction that the unobserved heterogeneity terms are zero $(\theta=0)$, while model 2 relaxes this assumption. In model 3 we introduce interaction terms between gender and the other explanatory variables. This should allow us to control for multicollinearity, as proposed by Mc Dowell et al. (2001). For each estimated model, robust $\mathrm{t}$-statistics are calculated (White, 1982). The results are 
presented in Table 3. They reflect the ceteris paribus effects of each covariate on the promotion duration. As accelerated failure-time models are estimated, a positive significant sign indicates that a given characteristic increases the duration to promotion, or equivalently decreases the promotion hazard.

First, let us focus on the importance of correcting for the unobserved heterogeneity. Model 2 provides an estimate of the $\theta$ parameter, which is significantly different from zero. This indicates that unobserved factors must be taken into account the model. We prefer therefore the model 2 to model 1, since neglecting the $v_{i}$ terms would introduce bias into the estimated effects, including the gender impact. More precisely, this would lead to a slight overestimate of the gender effect.

\section{[INSERT TABLE 3]}

Let us now look in at the effect of gender. As model 2 indicates an "average woman", i.e. a female researcher who would have the same characteristics than a male, has a longer wait until promotion. This result could be evidence of the glass ceiling hypothesis. But, more detailed comments can be made with the estimated hazard rate by gender (figure 1). These estimated hazards are evaluated for female and male average characteristics.

\section{[INSERT FIGURE 1]}


If women have on average lower predicted hazard rates, we observe that this general result is not uniform throughout the career. In the first half of the career, women have lower predicted hazard rates. But, women have slightly higher rates from 180 months onwards. This result is obtained after controlling from observed and unobserved factors. It cannot be explained by omitted individual attributes. A statistic explanation could be proposed. As females are promoted later than males (see below), females who have suitable competencies to be promoted are more numerous after 15 years career than male. We thus observe more females at risk in this period than males. Finally, the female promotion rate is higher. However, higher female hazard rates at the end of the career do not make up for the lower rates in the first half. Another point strengthens this conclusion. The peak of the female hazard rate occurs later and is lower than the male peak. Females are less likely promoted and when they are this tends to happen later. Thus, in spite of differences during the career, the existence of a glass ceiling could not to be rejected. This fits in with what Kahn (1993), Mc Dowell et al. (1999) or Ginther and Hayes (2003) have found for promotions in USA. Despite strong differences between the French academic system and those in the US and UK ones, female researchers at INRA also face greater difficulties of getting promoted than their male counterparts.

Apart from this general result, model 3 provides evidence of interaction between gender and other covariates. This suggests that gender affects both promotion duration directly but also indirectly through the effect on explanatory factors of promotion. For example, being a female Ph.D. advisor (HDR) or having been graduated from a top university (TOP_UNIV) boosts promotion to the "Senior 
Researcher" rank. The significant impact of these two variables is not surprising. Both generally act as a signal of higher competencies. More surprising is that these variables do not have a direct effect on promotion duration, that is no effect for men, but only a cross effect with the FEM variable. This could indicate that human capital accumulation through attending top universities and obtaining the "HDR" diploma are better exploited by females or that these signals play a greater role in the female promotion process than in the male one.

In contrast, mobility, captured through postdoctoral fellowships (POSTDOC) and mobility after entry at INRA (MOB), seems to produce a complex effect on female promotion. These two variables decrease the global promotion duration, which could confirm that mobility provides opportunities for networking and then accelerates promotions. But, for females, only mobility after the entry at INRA plays this role of a booster, whereas postdoctoral fellowships slow down their promotion. This finding could be explained in two ways. First, on the basis of sociological research on networking (Granovetter, 1973), it is possible that older networks become depreciated. This depreciation is, as for any capital, a natural process, but could be strengthened if relationships are not sustained. In our sample, females could have neglected their former networks, which have become inefficient. The second explanation is that postdoctoral fellowships held by female could be less in line with their recent research or more dedicated to teaching, as highlighted by Schneider (1998). Skills accumulated during this period would then not be essential for promotions at INRA, where researchers have no teaching duties. However, our data do not allow us to explore more these potential explanations in more detail. 
A third cross effect concerns gender and administrative activities, such as managing a research team (BOSS) or coordinating scientific projects (NPROJ_C), which slow down the promotion process for females. This finding is a bit surprising as administrative responsibilities are viewed at INRA as one of the promotion criteria. But, in our data, very few females are involved in this type of activity. Besides, these females seem to have more scientific achievements, in terms of publications. In contrast, researchers, mainly male, who have invested in management activities, have fewer publications. It could be that two strategies for promotion coexist: the first based on scientific achievements, publications or participating in projects, the second based on administrative responsibilities. In our data, the fact is that the choice of one of these two strategies seems to depend strongly on gender. Further investigations must be undertaken into the existence of this gender specialization

Beyond these interaction effects, our results confirm two of the findings in the previous literature. First, there are cohort effects on promotion duration (COH1). Promotions for younger cohorts are more difficult, probably because of a more competitive context: more researchers could apply for promotions positions, promotions are increasingly scarce. But, the cross effect between gender and cohort effect produces no significant effect. Unlike in Ramson and Magdal (1993) or Mc Dowell et al. (2001), the glass ceiling does not seem to be affected by a cohort effect. At INRA, no cracks in the glass ceiling appear. This could be explained by the fact that both women and men face the increased competition 
between researchers at INRA for promotions and gender does not matter in this particular framework.

We also find that publishing scores (PUB_SCORE) increase hazard rates. This confirms that publications are a criterion in promotion success. But, the positive effect of publications is true only for recent cohorts (COH1*PUB_SCORE). This could be explained by the fact that gathering information on publications and on their quality is more precise for recent cohorts (see footnote 4). Our cross effect allows us then to correct for the possibility that for past cohorts, publications may have been measured with error.

\section{$\underline{\text { IV-Conclusion }}$}

In spite of substantial evidence of the existence of a glass ceiling in French academia, no study has so far been undertaken to refute this hypothesis. We thus propose a first analysis of the promotion of French researchers. As there is no dataset available on researchers' careers, we begin by constructing a database which allows us to analyse the full career path and research activities of French researchers. We then focus attention on biologists' promotion duration to the senior rank at the National Institute for Agricultural Research. Using duration models, we conclude that females have a significantly lower hazard rate, in particular in the first half of their career, compared to their male counterparts. This result is obtained after controlling for both observed and unobserved heterogeneity. Furthermore, we find that gender does not have any uniform effect on promotion, but interacts with other covariates. This suggests that there exist accelerator and "slowing-down" factors for female promotion. Finally, our 
analysis does not refute the hypothesis that a glass ceiling limits the promotion of women at INRA.

\section{Acknowledgements:}

The authors are grateful to all the participants in the research project "Female careers in academia" and to Stephen Bazen for helpful comments on earlier drafts of the paper. Thanks also to the National Institute for Agricultural Research which provided access to the data and financial support. Any errors are our own. 


\section{$\underline{\text { References }}$}

Albrecht J., Bjorklund A., Vroman S. (2003), Is There a Glass Ceiling in Sweden?, Journal of Labor Economics, vol.21, ${ }^{\circ} 1$, pp.145-177.

Barbezat D. (1987), Salary Differentials by Sex in the Academic Labor Market, Journal of Human Resources, vol.22,n³,pp. 422-429.

Benjamin E. (1999), Disparities in the Salaries and Appointments of Academic Women and Men, Academe, vol.85, n¹, pp.60-62.

Delavault H., Boukhobza N., Hermann C. (2002), Les Enseignantes-chercheuses à l'Université - Demain la Parité ?, L'Harmattan.

Euwals R. and Ward M. (2000), The Remuneration of British Academics, IZA Discussion Paper, ${ }^{\circ} 178$.

Ginther D. (2001), Does Science Discriminate Against Women? Evidence from Academia 1977-1997, Federal Reserve Bank of Atlanta Working Paper, $\mathrm{n}^{\circ} 2$.

Ginther D., Hayes K. (2003), Gender Differences in Salary and Promotion for Faculty in the Humanities 1977-1995, Journal of Human Resources, vol.38, n¹, pp.34-73.

Ginther D., Hayes K. (1999), Gender Differences in Salary and Promotion in the Humanities, American Economic Review, vol.89, n², pp.397-402.

Granovetter M.S. (1973), The Strength of Weak Ties, American Journal of Sociology, vol.81, pp.12871380.

Joy L. (1998), Why Are Women Underrepresented in Public School Administration? An Empirical Test of Promotion Discrimination, Economics of Education Review, vol. 17, n², pp.193-204.

Kahn S. (1995), Women in the Economics Profession, Journal of Economic Perspectives, vol.9, n4, pp.193205.

Kahn S. (1993), Gender Differences in Academic Career Paths of Economists, American Economic Review Papers and Proceedings, vol.83, n`2, pp.52-56.

T. Lancaster (1990), The Econometric Analysis of Transition Data, Econometric Society Monographs, New York, Cambridge University Press.

Livre Blanc (2002), Les Femmes dans la Recherche Française, Ministère de la Recherche.

Long J., Allison P., R. McGinnis (1993), Rank Advancement in Academic Careers: Sex Differences and the Effects of Productivity, American Sociological Review, vol.58, n5, pp.703-722.

Mc Dowell J., Singell L., J. Ziliak (2001), Gender, Promotion in the Economic Profession, Industrial and Labor Relations Review, vol.54, n², pp.224-244.

Mixon F., Trevino L. (2005), Is there gender discrimination in named professorships? An Econometric analysis of economics departments in the US South, Applied Economics, vol. 37, pp.849-854.

Oaxaca R. (1973), Male-Female Wage Differentials in Urban Labor Markets, International Economic Review, vol.14, n³, pp.693-710.

Ransom M., S. Megdal (1993), Sex Differences in the Academic Labor Market in the Affirmative Action Era, Economics of Education Review, vol.12, n¹, pp.21-43.

Rapport ETAN (2000), Femmes et Sciences, Commission Européenne.

Schneider A. (1998), Why Don't Women Publish as Much as Men?, Chronicle of Higher Education, vol.45, nº pp.14-16.

Spurr S., Sueyoshi G. (1994), Turnover and promotion of Lawyers: An Inquiry into Gender Differences, Journal of Human Resources, vol.29, n³, pp.813-842.

Ward M. (2001)a, The Gender Salary Gap in British Academia, Applied Economics, vol. 33, n¹3, pp. $1669-1681$.

Ward M., (2001)b, Gender and Promotion in the Academic Profession, Scottish Journal of Political Economy, vol.48, n³, pp.283-302.

White H. (1982), "Maximum Likelihood Estimation of Misspecified Models", Econometrica, n53, pp.16. 
Table 1: Proportion of researchers in senior rank positions

\begin{tabular}{|l|c|c|}
\hline & Men & Women \\
\hline INRA & $51 \%$ & $15 \%$ \\
\hline Universities & $43 \%$ & $18 \%$ \\
\hline Public research institutes & $45 \%$ & $25 \%$ \\
\hline
\end{tabular}

Source: Livre Blanc, 2002 
Table 2: Descriptive statistics

\begin{tabular}{|c|c|c|c|c|c|c|}
\hline Variables & Full sample & $\begin{array}{c}\text { Senior } \\
\text { Researchers }\end{array}$ & $\begin{array}{c}\text { Female } \\
\text { Researchers }\end{array}$ & $\begin{array}{c}\text { Male } \\
\text { Researchers }\end{array}$ & $\begin{array}{c}\text { Female Senior } \\
\text { Researchers }\end{array}$ & $\begin{array}{l}\text { Male Senior } \\
\text { Researchers }\end{array}$ \\
\hline FEM: being female & $37.4 \%$ & $17.4 \%$ & - & - & - & - \\
\hline TOP_UNIV: graduated from a top university & $25.6 \%$ & $45 \%$ & $14.6 \%$ & $33.3 \%$ & $17.7 \%$ & $47.4 \%$ \\
\hline HDR: having the PhD. Advisor diploma & $11.1 \%$ & $16.4 \%$ & $4.3 \%$ & $45.4 \%$ & $12.4 \%$ & $10.3 \%$ \\
\hline POSTDOC: having been a postdoctoral fellowship & $14.2 \%$ & $6.3 \%$ & $19.5 \%$ & $16.7 \%$ & $3.0 \%$ & $7.0 \%$ \\
\hline MOB: mobility since entry at INRA & $19.4 \%$ & $20.6 \%$ & $17.8 \%$ & $19.6 \%$ & $12.1 \%$ & $22.4 \%$ \\
\hline PROM: being promoted to senior position & $32.4 \%$ & - & - & - & - & - \\
\hline COH1: hired before 1980 & $28.7 \%$ & $64.6 \%$ & $5.4 \%$ & $16.7 \%$ & $42.4 \%$ & $69.3 \%$ \\
\hline PUB_SCORE: publication productivity & 20.36 & 15.1 & 17.2 & 32.0 & 27.4 & 11.5 \\
\hline NPROJECT: number of projects & 1.2 & 1.5 & 0.9 & 2.2 & 1.3 & 1.3 \\
\hline NPROJ_C: number of projects coordinated & 0.5 & 0.4 & 0.3 & 0.7 & 0.4 & 0.6 \\
\hline NETW: having networking activities & $10.5 \%$ & $18.5 \%$ & $4.9 \%$ & $24.2 \%$ & $8.1 \%$ & $17.3 \%$ \\
\hline BOSS: managing team or laboratory & $12.7 \%$ & $33.9 \%$ & $2.2 \%$ & $24.2 \%$ & $2.9 \%$ & $35.9 \%$ \\
\hline COMMIT: participating to strategic committees & $4.6 \%$ & $9.5 \%$ & $1.1 \%$ & $9.1 \%$ & $3.3 \%$ & $9.6 \%$ \\
\hline Observations & 583 & 189 & 185 & 209 & 33 & 156 \\
\hline
\end{tabular}


Table 3: The determinants of promotion duration

\begin{tabular}{|c|c|c|c|c|c|c|}
\hline \multirow[b]{2}{*}{ Explanatory factors } & \multicolumn{2}{|c|}{ Model 1} & \multicolumn{2}{|c|}{ Model 2} & \multicolumn{2}{|c|}{ Model 3} \\
\hline & Coeff. & t-ratios & Coeff. & t-ratios & Coeff. & t-ratios \\
\hline Constant & 5.48 & $9.29^{\star \star \star}$ & 5.21 & $8.20^{\star \star \star}$ & 5.17 & $4.26^{\star \star \star}$ \\
\hline FEM: being female & 0.20 & $2.54^{\star \star}$ & 0.16 & $2.42^{\star \star}$ & 0.09 & $0.72^{n s}$ \\
\hline COH1: hired before 1980 & -0.24 & $-3.08^{\star * \star}$ & -0.28 & $-4.19^{\star \star \star}$ & -0.27 & $-3.78^{\star \star \star}$ \\
\hline TOP_UNIV: graduated from a top university & 0.02 & $0.07^{n s}$ & 0.01 & $0.02^{n s}$ & 0.06 & $1.01^{n s}$ \\
\hline HDR: having the PhD. Advisor diploma & -0.21 & $-2.48^{\star \star \star}$ & -0.08 & $-1.13^{n s}$ & 0.09 & $1.02^{n s}$ \\
\hline POSTDOC: having been a postdoctoral fellowship & -0.01 & $-0.08^{n s}$ & -0.06 & $-0.66^{n s}$ & -0.23 & $-2.35^{\star \star}$ \\
\hline MOB: mobility since entry at INRA & -0.03 & $-2.17^{* *}$ & -0.02 & $-2.13^{\star \star}$ & -0.01 & $-2.22^{\star *}$ \\
\hline NPROJECT: number of projects & -1.21 & $-2.08^{* *}$ & -0.81 & $-1.80^{*}$ & -2.44 & $-1.78^{*}$ \\
\hline NPROJ_C: number of projects coordinated & -8.78 & $-4.25^{\star \star \star}$ & -6.38 & $-3.51^{\star \star *}$ & -4.24 & $-1.92^{*}$ \\
\hline PUB_SCORE: publication productivity & -0.06 & $-0.53^{n s}$ & -0.16 & $-1.74^{*}$ & -0.19 & $-1.75^{\star}$ \\
\hline BOSS: managing team or laboratory & -0.36 & $-5.07^{* * *}$ & -0.18 & $-2.89^{\star \star *}$ & -0.19 & $-3.06^{\star * \star}$ \\
\hline NETW: having networking activities & -0.10 & $-1.29^{n s}$ & -0.07 & $-1.00^{n s}$ & -0.07 & $-1.04^{n s}$ \\
\hline COMMIT: participating to strategic committees & -0.01 & $-0.10^{n s}$ & -0.01 & $-0.15^{n s}$ & -0.01 & $-0.27^{n s}$ \\
\hline $\mathrm{COH} 1^{*}$ PUB_SCORE & 1.07 & $2.03^{* *}$ & 0.98 & $2.76^{\star \star \star}$ & 1.14 & $2.71^{\star \star \star}$ \\
\hline \multicolumn{7}{|l|}{-} \\
\hline $\mathrm{FEM}^{*} \mathrm{COH} 1$ & & & & & -0.20 & $-1.16^{n s}$ \\
\hline FEM ${ }^{*} T O P \_U N I V$ & & & & & -0.35 & $-2.74^{\star * *}$ \\
\hline FEM ${ }^{*} \mathrm{HDR}$ & & & & & -0.46 & $-2.99^{\star \star \star}$ \\
\hline FEM ${ }^{*}$ POSTDOC & & & & & 0.71 & $2.87^{* * *}$ \\
\hline FEM ${ }^{*} \mathrm{MOB}$ & & & & & -0.07 & $-2.01^{\star \star}$ \\
\hline FEMNPROJECT & & & & & -0.89 & $-2.07^{\star \star}$ \\
\hline FEM ${ }^{*}$ NPROJ_C & & & & & 2.02 & $2.02^{\star \star}$ \\
\hline FEM*PUB_SCORE & & & & & 0.23 & $0.87^{n s}$ \\
\hline FEM $^{*}$ BOSS & & & & & 0.39 & $2.07^{\star \star}$ \\
\hline FEM $^{\star}$ NETW & & & & & -0.15 & $-0.80^{n S}$ \\
\hline $\mathrm{FEM}^{*} \mathrm{COMMIT}$ & & & & & 0.17 & $1.26^{n s}$ \\
\hline Sigma & 0.29 & $16.88^{\star \star \star}$ & 0.17 & $9.86^{\star \star \star}$ & 0.15 & $9.90^{\star \star \star}$ \\
\hline Theta & - & - & 1.50 & $4.20^{\star \star \star}$ & 1.69 & $4.72^{\star \star \star *}$ \\
\hline \begin{tabular}{|l} 
Log-Likelihood \\
\end{tabular} & -25 & 0.76 & -23 & 2.52 & & \\
\hline Observations & & & & & & \\
\hline
\end{tabular}

NB: Estimated coefficients are rounded to two decimal places. Robust t-ratios (using heteroscedastic-consistent errors from White's (1982) procedure) are reported.

with: ${ }^{* *}$ : statically significant at $1 \%$ level, ${ }^{* *}$ : significant at $5 \%$ level, ${ }^{*}$ : significant at $10 \%$ level and ns: non significant 
Figure 1: Predicted hazard rates by gender (model 2)

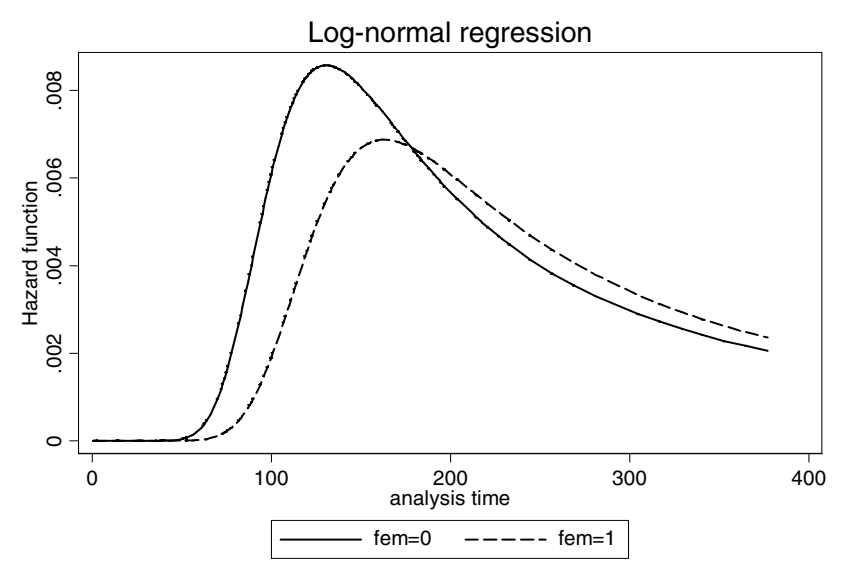




\title{
Do Female Researchers Face a Glass Ceiling in France? A HAZARd Model of Promotions
}

First draft

\author{
Mareva Sabatier* \\ * IREGE, IMUS, Université de Savoie, France \\ mareva.sabatier@univ-savoie.fr
}

\section{Abstract:}

The present article examines whether French female researchers face a glass ceiling, an invisible barrier to promotion. Using an original database from the National Institute for Agricultural Research, we estimate duration models for promotions. The methodology used allowed us to take into account censored observations and unobserved heterogeneity. Our results show a significant gender effect that does not contradict the glass-ceiling hypothesis. In addition, factors that boost promotion seem to be radically different according to gender and we present evidence that promotion strategies are different for males and females.

Keywords: Promotion, Glass Ceiling, Gender Gap Code JEL: J16, C41 


\section{$\underline{\text { I- Introduction }}$}

Whatever the profession (Altonji \& Blank, 1999, for an overview and Albrecht, et al., 2003; Joy, 1998; Spurr \& Sueyoshi, 1994, for studies of specific jobs), the literature provides a large amount of evidence for gender-related differences in earnings and promotion. Focusing on promotion, females seem to be underrepresented in senior positions, suggesting that women face a glass ceiling that limits their promotion. This glass ceiling is a result of gender discrimination, which, like other forms of discrimination, is socially unacceptable. However, the glass-ceiling phenomenon may also generate negative incentives for women (because they are less likely to be promoted, they could, quite rationally, invest less in their work), depriving the economy of competencies that could be used more efficiently. These social and economic costs have provided a driving factor for research into the existence and effects of a glass ceiling.

In academia, the question of whether or not a glass ceiling exists is all the more interesting because this sector is attracting increasing numbers of women; therefore, negative incentives may generate higher costs than in other sectors. Nevertheless, Benjamin (1999) notes that academia does not seem to have escaped the glass-ceiling phenomenon. The ETAN Report (2000) states that, in all OECD countries, the proportion of females decreases further up the rank ladder. On average, there are three times as many women in "assistant" positions (30.5\% are women) and twice as many women in "lecturer" positions (20.5\% are women) than in "full professor" positions (10.4\%).

These statistics seem to be consistent with the presence of a glass ceiling but observed gender differences among academics could be caused by gender 
disparities in the different areas of academia. For example, Schneider (1998) notes that a greater proportion of women are involved in teaching activities, which could explain why women tend to publish less and why they are less likely to be promoted.

In order to establish the existence of a glass ceiling in academia, other factors that affect careers must be taken into account. Econometric analyses are thus required in order to obtain ceteris paribus evaluations of the situation facing women.

However, microeconometric studies are relatively scarce and most of them have focused on wages. Studies carried out using Mincer equations generally find significant wage gaps between men and women, even after controlling for individual characteristics, publication scores and department characteristics, etc. Using American data from the Survey of Doctorate Recipients (SDR), Ginther and Hayes (1999) calculated the gender gap in Human Sciences to be $9 \%$ in favour of men. According to Ward (2001), women in Scottish academia earn 26\% less than their male counterparts. Although these studies do not refute the glass-ceiling hypothesis, they show that the phenomenon may not be clear-cut. First, the gender wage gap has decreased since the 1970's (Ransom \& Megdal, 1993). Second, estimated wage gaps are mainly caused by gender differences in observable heterogeneity. For example, by applying an Oaxaca decomposition, Ward (2001) showed that only three percentage points of the estimated $26 \%$ difference in wages can be attributed to discrimination. Ginther and Hayes (2003) confirmed this result and demonstrated that gender wage gaps are mostly due to gender rank differentials. This suggests that wages are directly related to rank. 
More recently, research has focused on the promotion process. Ginther and Hayes (2003) estimated promotion probabilities using univariate probit models. They concluded that women in the Human Sciences are significantly less likely to be promoted to tenured positions, ceteris paribus: the estimated gap is about $8 \%$. Similarly, Mixon and Trevino (2005) reported discrimination against female economists in the US South. Applying the Oaxaca decomposition to a logit model of promotion, they found that the promotion probability is 12.2 percentage points lower for females and that 7.6 of these 12.2 points cannot be explained by differences in productivity and are therefore due to discrimination.

The glass ceiling can still be seen when the dynamic process of promotion is taken into account. Using a random-effects probit model, Mc Dowell et al. (1999) concluded that the "average woman" is $36 \%$ less likely to be promoted to the "assistant professor" rank and 9\% less likely to be promoted to the "full professor" rank. Similarly, Kahn (1993) found that the risk ratio for female economists obtaining tenure is about two-thirds of the male ratio. Ginther and Hayes (2003) found similar results in the Humanities, where the estimated gender gap in promotion rates is large: women are $25 \%$ less likely to be promoted, ceteris paribus.

The empirical literature does not refute the hypothesis that women are less likely to gain access to senior positions, which suggests that a glass ceiling does exist for academics, whatever discipline they are in. However, existing results are based on data from America or the United Kingdom, countries that have very similar academic systems, and it could be argued that gender gaps result from certain characteristics of these systems that are unfair to females. Therefore, it would be 
interesting to test the glass-ceiling hypothesis in another type of academic system. In this respect, the French system provides an interesting alternative, as French academia has a number of specific features that set it apart from the American or British systems (see Ginther (2001) and Euwals \& Ward (2000) for detailed descriptions of these two academic systems).

Firstly, in contrast to other countries, the French academic sector has two branches: universities and national research laboratories. Each branch is independent and has its own working rules. For example, researchers working in the national research institutes have no teaching duties, unlike those working in universities.

Secondly, in the USA or the United Kingdom, academic careers are dominated by tenure rules. After completing a Ph.D., a young researcher is hired as an assistant professor on a fixed term contract. Tenured status (as a Full Professor) is not awarded until later in an academic's career and this status is not offered to all academics. Promotion criteria include scientific achievements, such as the number of papers published and their quality. French academia is organised quite differently. A key difference that applies to all French institutions (universities and national research laboratories) and all disciplines is that lifetime contracts are awarded soon after hiring. Recruitment is based on the quality of the research carried out during the Ph.D., but researchers become tenured civil servants after only 12 months' probation and this occurs almost automatically. Civil servant status implies a life-long job and, for a given rank, a fixed wage scale. There are two main and equivalent ranks in French academia: assistant professor and full professor in the university system and researcher and senior researcher in the 
national research laboratories. Salaries for each rank and status are fixed by a national collective agreement and are the same for all universities and research laboratories. Academics at the same level in the hierarchy all receive the same salary.

In France, the objective of seeking promotion is not to get tenure (since this is automatic) but to earn a higher salary and to obtain greater responsibilities (such as being a Ph.D. supervisor or managing a team of researchers). As in other countries, promotion to the senior rank depends on scientific achievements, which are evaluated by promotion committees.

Another difference is that all disciplines in French academia are organized according to this general framework and they all follow the same general hiring and career rules. As stressed in the stylized facts, an examination of the promotion process reveals large differences between the genders. This suggests that, despite the differences between the French and American/British academic sectors, French female researchers are also under-represented in the senior ranks and, therefore, a glass ceiling exists.

The aim of this article is to test whether a study of promotion paths supports this hypothesis. As in the literature, we will take into account both observed heterogeneity, such as individual attributes and scientific achievements, which can explain promotion gaps, and unobserved heterogeneity, which are often neglected. As career paths in French academia can only be described by changes 
in rank, the gender effect is evaluated according to the probability of becoming a senior researcher.

In order to carry out this research, we had to overcome a major obstacle: there is no generally available data set on academic careers in France. In section two, we explain how we constructed a panel data set for researchers' careers. This data set allowed us to examine the career paths of a group of biologists working at the National Institute for Agricultural Research (INRA), one of France's national research institutes. By focusing on life scientists at a single institute we were able produce homogenous data that could be used to test the glass-ceiling hypothesis, thereby providing the first study of this phenomenon in France.

\section{II- The Data}

As there is no official dataset describing the career paths of researchers in France, we constructed one, using information from the administrative files of INRA. INRA was founded in 1946 to develop scientific knowledge in the fields of agriculture, food and the environment. In terms of publications in these fields, INRA ranked is second in the world. In 2002, INRA had 260 research departments and employed about 1,800 researchers, $37 \%$ of whom were female. As in other national research institutes, INRA's researchers are divided into two ranks: researchers and senior researchers. In 2002, 35\% of INRA's researchers held the senior researcher rank.

Also like other national research institutes, there is almost gender parity amongst researchers but women are under-represented amongst senior researchers: only $5.5 \%$ of researchers are female senior researchers. Furthermore, the situation for 
female researchers at INRA is worse than at other public research institutes or universities. Table 1 shows that the proportion of senior researchers among women is ten percentage points lower at INRA than at other public institutes.

\section{[INSERT TABLE 1]}

Most of the scientists recruited by INRA are hired as researchers, with promotion to the senior researcher rank, if justified, being awarded later in their careers ${ }^{1}$. Our research focused on this particular promotion path. Promotion to the senior researcher rank mainly occurs through a formal, internal, competitive process that begins with the publication of available positions on INRA's website or in journals. In order to apply, applicants must fulfil certain eligibility criteria, including possession of a Ph.D. and at least eight experience years (at INRA or another research institution). Applicants must submit their CV together with outlines of their previous research activities (mostly carried out while at INRA) and of their future projects. Applications are examined by promotion committees composed of researchers from INRA and other institutes or universities, who draw up a short list of the most suitable, eligible candidates. These short-listed candidates are then interviewed, ranked and eventually promoted.

This description of the promotion process at INRA highlights the fact that applications for senior posts are mostly endogenous. Researchers' decisions to apply for senior researcher posts are usually based on seniority, the quality of their scientific work and the number of positions available. The probability of applying must therefore be examined. Unfortunately, our administrative dataset

\footnotetext{
${ }^{1}$ In recent years, a small number of scientists have been recruited directly as senior researchers. As this type of career path does not constitute promotion within INRA it was not analysed in this study.
} 
only provides information about promotion decisions and not about applications. Furthermore, no details are provided about decisions concerning the eligibility of applicants or the number of positions available. In order to minimize bias, the empirical part of our study focused on researchers who have sufficient experience to be promoted. Nevertheless, the potential endogeneity bias could not be fully controlled in our study and our results must therefore be interpreted with caution.

Despite this limitation, the dataset allowed us to observe individuals' entire careers at INRA and the length of time people stay at the researcher rank before being promoted to senior researcher. Section three of the present article investigates whether gender has a significant effect on this duration, which is sometimes right-censored.

Of the researchers at INRA, we decided to focus on the 583 researchers in biology, INRA's main discipline. In order to describe their career paths, we combined two administrative data sets. The first lists the length of time spent in each rank; the second contains the activity reports each researcher supplies for his or her annual evaluation. These data are collected from the time a researcher begins work at INRA until the date that person is promoted to a senior researcher position, or to the end of 2002, if he or she is still at the researcher grade at this time. From the 583 researchers observed, we selected individuals for further study on the basis of two criteria: they had to have had more than eight years' experience at INRA and they had to have been recruited during a year in which both male and female researchers were recruited. These two criteria allowed us to focus on researchers 
who fulfilled the eligibility criteria for promotion and to compare cohorts containing both male and female subjects. Our final sample contained 357 researchers.

These 357 researchers were then divided into a number of cohorts. Following the example of Ransom and Megdal (1993), we created a dummy variable, COH1 (hired by INRA before 1980), in order to capture cohort effects, which could, for instance, be produced by changes in the promotion process. In fact, in recent years recruitment and promotion procedures in the French academic sector as a whole seem to have become more competitive than they were in the early eighties.

We also had information about several individual attributes. For example, we know which researchers graduated from the "Grandes Ecoles", France's top universities (TOP_UNIV), which are considered to attract the best students. We also know if a researcher can supervise Ph.D. students, a role for which a specific diploma $\left(\mathrm{HDR}^{2}\right)$ is required. These two variables, TOP_UNIV and HDR are likely to indicate a higher human capital and play a role in the promotion process.

Our data also contain information on a researcher's mobility. This mobility could be due to undertaking a postdoctoral fellowship (POSTDOC), a visiting professorship, or a sabbatical abroad after being hired at INRA (MOB). Mobility is often viewed as an opportunity for acquiring new competencies and for networking. Networks built up within the scientific community provide greater

\footnotetext{
${ }^{2}$ In order to obtain an "HDR" diploma, also known as a "Habilitation", a candidate must prepare a written document outlining his or her contribution to science. As for a Ph.D., this document must then be defended in front of a jury.
} 
opportunities for cooperation and can increase scientific achievement; therefore mobility can increase the chances of promotion.

In contrast to other data sets described in the literature, our sample contained information on all aspects of a researcher's work, including each researcher's publication record. These publication records were combined with data from the Science Citation Index, which provides an impact factor (based on the journal quality index $)^{3}$ for each publication, in order to construct a publishing score (articles published weighted by journal quality) that reflects publishing productivity (PUB_SCORE). Like McDowell et al. (2001), we preferred this mixed indicator to a simple quantitative measure of publications, which does not take into account the impact or reputation of the scientific work. In addition, we also had information about each researcher's degree of involvement in scientific projects (as a participant, NPROJECT, or a coordinator, NPROJ_C) and in administrative activities. These activities include managing a research team or a department (BOSS), or networking activities, such as belonging to a professional body (NETW) or membership of strategic, recruitment or promotion committees (COMMIT). All these attributes provided us with more detailed information on a researcher's scientific achievements and reputation, which are pillars of the promotion criteria.

However, the richness of our data set may have a negative counterpart: scientific work might be endogenous. For example, the most highly motivated researchers could be the ones who do the most research and contribute most to the literature,

\footnotetext{
3 The impact factor is complete for all publications from the early 1980's onwards, but it may be more imprecise for earlier publications. This must then be taken into account in the econometric results and comments. We therefore introduced a cross variable between COH1 and PUB_SCORE, in order to treat the potential collinearity.
} 
and who are the most likely to be promoted. But, valid instruments are needed to identify these processes. Unfortunately, our dataset is not informative enough to allow us to test both the determinants of scientific achievement and those of length of service before promotion.

In addition, our administrative data set does not provide information on personal characteristics, such as marital status and number of children, or on the activities of each research department. Previous studies have found these variables have a significant effect on the promotion process; therefore, neglecting them could generate an omitted-variable bias. This point will be discussed in the following section.

Table 2 provides descriptive statistics for the whole sample and for sub-samples determined according to gender and/or grade. Among the 327 individuals in the sample, $35.6 \%$ were female and $40.9 \%$ were senior researchers. However, only $19.2 \%$ of women held senior positions. These figures are very similar to the general situation at INRA (i.e. for all disciplines): women are under-represented in the highest ranks.

\section{[INSERT TABLE 2]}

For some staff promotion duration (defined in months) is right-censored; however, the median time taken to achieve promotion is 136 months, with the median time for males being 8 months less than the median time for females. In order to take into account censored observations, we estimated simple Kaplan Meier survival rates on yearly intervals.

[INSERT FIGURE 1] 
Non-parametric hazard rates highlight the fact that, throughout a person's career, the hazard rate for females is always lower than the hazard rate for males: the cumulative hazard rate is about $77 \%$ for males but only $49.2 \%$ for females.

However, this difference could be caused by gender differences in other variables that affect promotion (see Table 2). First, large differences exist between individuals who have been promoted to the senior researcher rank and those still at the researcher rank. In general, staff promoted to the senior researcher rank joined INRA at an earlier date: 64.4\% were hired before 1980 (only 32\% in the full sample). More surprisingly, senior researchers had lower publishing scores (at the hiring date) and were more involved in administrative activities. Second, female senior researchers had specific characteristics. In general, they had been hired more recently than male senior researchers, they had higher publishing scores than the males and they carried out fewer administrative activities.

As the general profiles of senior researchers and of female staff were very different, it was necessary to carry out an econometric analysis of the dataset in order to evaluate the gender gap in promotion rates at INRA.

\section{III - Modelling the determinants of promotion duration}

The descriptive evidence clearly indicates that women are under-represented in senior researcher positions at INRA. Our aim was to test whether this gender differential remains after controlling for observed and unobserved heterogeneity. Instead of estimating the probability of being promoted (as in Mixon \& Trevino, 2005), we focused on the hazard rate, denoted $\lambda_{i}(t)$. This allowed us to take into 
account both the dynamic dimension of the promotion process and potential unobserved heterogeneity terms, which can bias estimations. This hazard rate can be expressed as follows:

$$
\lambda_{i}(t)=\frac{p(t \leq T<t+d t / T \geq t)}{p(T \geq t)}=\frac{f(t)}{S(t)}
$$

where $T$ is the length of time (in months) spent at the researcher grade, $f(t)$ is the density distribution and $S(t)$ the survival function.

Using the model of Mc Dowell et al. (1999), $\lambda$ can be viewed as the probability at time $t$ that an individual's productivity exceeds the department productivity threshold (probability of being promoted), given that this productivity is lower than the threshold at least until $t$ (probability of being not promoted until $t$ ). As both individual productivity and the productivity norm for the department are latent variables, $\lambda$ denotes the probability of becoming a senior researcher, given that no promotion occurs before $t$.

Estimations of this hazard rate were performed using duration models (Lancaster, 1990), which allowed us to take into account the fact that $67.6 \%$ of the individuals studied were still at the researcher grade at the sampling date; that is to say, more than two thirds of the observed durations were right-censored. We estimated a parametric model (with an accelerated failure-time form) that allowed us to control for both observed and unobserved explanatory factors. Kaplan-Meier estimates have shown that hazard rates are non-monotonic, and therefore a loglogistic distribution ${ }^{4}$ was applied.

\footnotetext{
${ }^{4}$ Various specifications for distributions of durations (log-normal, weibull, etc) were tested. The results were not affected by the specifications chosen.
} 
In our parametric specification, the hazard rate, $\lambda_{i}$, was assumed to depend on three factors: a vector of observable characteristics $X_{i}$, an individual specific effect, $v_{i}$ and an error term $\varepsilon_{i}$.

The $X$ vector included gender, mobility characteristics, publishing score, investment in projects and administrative activities. The $v_{i}$ term was added to capture individual unobserved heterogeneity. Using panel models, Mc Dowell et al. (2001) pointed out that neglecting unobserved heterogeneity could cause endogeneity bias and lead to spurious results. Several attributes, such as number of children, marital status and the characteristics of the research department, were missing from the administrative dataset used for our study. As noted earlier, studies have shown that these variables have significant effects; therefore, their omission increases the risk of endogeneity bias. We were able to overcome this difficulty by modelling $v_{i}$, a term with a gamma distribution $\left(\Gamma\left(v_{i}\right)\right)$, unit mean and variance $\theta$.

The survival function, denoted $S(t)$, can then be written as follows:

$$
S\left(t_{i}\right)=\int_{v_{i}} S\left(t_{i} \mid v_{i}\right) f\left(v_{i}\right) d v_{i}
$$

with:

- $\quad S\left(t_{i} / v_{i}\right)=\Phi\left[-\sigma \ln \left(\lambda_{i} t_{i}\right)\right]$

(3)

where $\lambda_{i}=e^{-\beta^{\prime} X_{i}}, t_{i}$ is the promotion duration and $\Phi$ is the cumulative distribution function for the standard normal distribution, and: 
- $f\left(v_{i}\right)=\frac{k^{k}}{\Gamma(k)} e^{-k v_{i}} v_{i}^{k-1}$, where $k=\frac{1}{\theta}$

From this general specification, three different models were estimated. Model 1 estimated the effect of gender on promotion duration for the whole sample, including both the observed and the unobserved heterogeneity. Models 2 and 3 gave results by gender in order to test whether or not the effects of explanatory variables on promotion duration are gender dependent.

For each estimated model, robust t-statistics were calculated (White, 1982). The results are presented in Table 4 . They reflect the ceteris paribus effects of each covariate on the promotion duration. Time ratios are also given. A time ratio lower (higher) than one indicates that the characteristic decreases (increases) promotion duration. Time ratios provide interesting information because, as well as giving the sign of the effect of a variable, they enable its quantitative effect to be evaluated by indicating how much the promotion duration increases or decreases for a given explanatory variable. For example, if the time ratio of a covariate $\mathrm{X}$ is 1.21 , the promotion duration for researchers with the $\mathrm{X}$ attribute will be 1.21 times higher than the duration for researchers lacking this caracteristic, ceteris paribus.

Model 1 shows the importance of correcting for unobserved heterogeneity, in that it provides an estimate of the $\theta$ parameter, which is significantly different from zero. Thus the model must take into account unobserved factors, as neglecting the $v_{i}$ terms would introduce bias into the estimated effects, including the impact of gender. 


\section{[INSERT TABLE 4]}

Model 1 also allows us to examine the effect of gender. The model shows that an "average woman", i.e. a female researcher with the same characteristics as a male researcher, has to wait longer for promotion. Promotion durations for females are 1.12 times longer than for their male counterparts. Gender is one of the variables with the highest effect on promotion duration.

This result supports the glass-ceiling hypothesis; however, a more detailed picture can be revealed by examining estimated hazard rates by gender (Figure 2). These estimated hazard rates were evaluated for female and male average characteristics.

\section{[INSERT FIGURE 2]}

Although women had lower predicted hazard rates, on average, than men, we observed that this overall result does not apply throughout women's careers. In the first half of their careers, women had lower predicted hazard rates but, after 180 months, their hazard rates were slightly higher. This result was obtained after controlling for observed and unobserved factors. It cannot be explained by omitted individual attributes; however, a statistical explanation is possible. As females are promoted later than males (see below), after 15 years employment females with the competencies needed for promotion are more numerous than males. Thus, at this stage in their careers, we observe more females at risk than males. Finally, the promotion rate for females is higher than that for men. However, the higher hazard rates for females in the second half of their careers do not compensate for the lower hazard rates in the first half. This conclusion is 
strengthened by the fact that the female hazard rate peaks later and at a lower value than the male hazard rate. Females are less likely to be promoted and when they are promoted it tends to be later in their careers. Hence, although there are differences in the career patterns of female and male researchers, a glass ceiling still seems to exist. This is consistent with the findings on promotions in the USA reported by Kahn (1993), Mc Dowell et al. (1999), and Ginther and Hayes (2003). Although there are major differences between the French academic system and the American and British systems, female researchers at INRA still find it more difficult to gain promotion than their male counterparts.

As well as gender, promotion durations also seem to be affected by recruitment date. Our results show that older cohorts were promoted more quickly than more recent cohorts. For example, the promotion duration for personnel recruited before 1980 was 0.89 times that of more recent cohorts. This could be due to a less competitive recruitment environment before 1980, to a greater availability of promotions, and/or to fewer researchers being eligible for promotion. Among scientific achievements, which are the main criteria for promotion, the most influential variable is BOSS. Managing a team reduces promotion durations by a factor of 0.81 . Developing and coordinating projects also shorten promotion durations, but the publication score (PUB_SCORE) has no significant effect. Hence, it seems that the promotion criteria do not all have the same effect on promotion duration and that investing in managerial activities is more profitable than carrying out research in terms of achieving promotion.

Models 2 and 3 provide evidence of interaction between gender and other variables, suggesting that gender affects promotion duration both directly and 
indirectly through its effect on the explanatory factors of promotion. A different career path can be identified for each gender. For females, promotion is accelerated by higher scientific production in terms of publication score (PUB_SCORE) or projects (NPROJECT), whereas for males promotion is accelerated by managerial achievements (managing a research team (BOSS) or coordinating projects (NPROJ_C)). This result indicates the coexistence of two strategies for promotion: the first based on scientific achievements, publications or participation in projects, the second based on managerial responsibilities. Our data suggests that the choice of strategy depends strongly on gender. Further work is needed to confirm the existence of such gender-based specialization.

Estimates of promotion duration by gender highlight that unobserved heterogeneity only affect the promotion duration of females (see model 3). This could be explained by the fact that our dataset does not included attributes such as marital status, number of children and career interruptions due to motherhood. Recent studies have shown that these factors do affect women's careers.

Our promotion duration models allowed us to make a number of predictions and simulations.

\section{[INSERT TABLE 4]}

The results of model 1 were used to estimate the median promotion durations for males and females. When censored observations, and unobserved and observed covariates were taken into account, we found that females have to wait about 2.75 years longer for promotion than males. However, simulations carried out with female attributes evaluated equally to male attributes (using $\hat{\beta}_{\text {male }}$ ), and inversely, with male attributes evaluated equally to female attributes (using models 2 and 
3), gave longer promotion durations than those predicted by model 1 . However, the gender gap in these simulated promotion durations was still less than one year in favour of men. In fact, in the hypothetical case of male attributes being evaluated equally to female attributes, the simulated promotion duration for males would be 2.8 years longer than the predicted duration. For females, the simulated promotion duration was only 1 year longer. This result seems to show that promotion duration is not only affected by gender differences in the covariates but also by the way these covariates are evaluated.

\section{$\underline{\text { IV-Conclusion }}$}

Although there is substantial evidence for a glass ceiling in French academia, no previous attempts had been made to prove or disprove its existence. Therefore, the present study is the first to investigate whether the promotion durations of French researchers are dependent on gender. As there was no available dataset on researchers' careers, we began by constructing a database that would allow us to analyse complete career paths and research activities of French researchers. Focusing on biologists at the National Institute for Agricultural Research, we examined promotion durations for elevation to the senior researcher rank. Our duration models show that females have significantly lower hazard rates, in particular in the first half of their careers, than their male counterparts. This result was obtained after controlling for both observed and unobserved heterogeneity. We also found that the explanatory factors for promotion durations are very different for the two genders. This seems to suggest a sort of gender 
specialisation, with greater scientific achievements providing the fastest route to promotion for female researchers and greater managerial responsibilities being the best way of ensuring promotion for male researchers.

Our analysis does not refute the hypothesis that the promotion of women at INRA is limited by a glass ceiling; however, further research is needed to investigate the effects of the differences in the promotion strategies adopted by male and female researchers.

\section{Acknowledgments:}

The authors are grateful to all the participants in the research project "Female careers in academia", especially Christine Musselin and Vincent Mangematin. We would also like to thank Stephen Bazen and Bart Cockx, for their helpful comments on earlier drafts of the paper, as well as the National Institute for Agricultural Research, for providing access to the data and financial support. Any errors are our own.

\section{$\underline{\text { References }}$}

Albrecht J., Bjorklund A., Vroman S. (2003), Is There a Glass Ceiling in Sweden?, Journal of Labor Economics, vol.21, ${ }^{\circ} 1$, pp.145-177.

Altonji, J. G., Blank, R. M. (1999), Race and Gender in Labor Market, Handbook of Labor Economics, vol. 3C, pp. 3143-3259.

Barbezat D. (1987), Salary Differentials by Sex in the Academic Labor Market, Journal of Human Resources, vol.22,n³,pp. 422-429.

Benjamin E. (1999), Disparities in the Salaries and Appointments of Academic Women and Men, Academe, vol.85, n ${ }^{\circ}$, pp.60-62.

Delavault H., Boukhobza N., Hermann C. (2002), Les Enseignantes-chercheuses à l'Université - Demain la Parité ?, L'Harmattan.

Euwals R. and Ward M. (2000), The Remuneration of British Academics, IZA Discussion Paper, ${ }^{\circ} 178$. 
Ginther D. (2001), Does Science Discriminate Against Women? Evidence from Academia 1977-1997, Federal Reserve Bank of Atlanta Working Paper, $\mathrm{n}^{\circ} 2$.

Ginther D., Hayes K. (2003), Gender Differences in Salary and Promotion for Faculty in the Humanities 1977-1995, Journal of Human Resources, vol.38, n¹, pp.34-73.

Ginther D., Hayes K. (1999), Gender Differences in Salary and Promotion in the Humanities, American Economic Review, vol.89, n², pp.397-402.

Granovetter M.S. (1973), The Strength of Weak Ties, American Journal of Sociology, vol.81, pp.12871380.

Joy L. (1998), Why Are Women Underrepresented in Public School Administration? An Empirical Test of Promotion Discrimination, Economics of Education Review, vol. 17, n², pp.193-204.

Kahn S. (1995), Women in the Economics Profession, Journal of Economic Perspectives, vol.9, n4, pp.193205.

Kahn S. (1993), Gender Differences in Academic Career Paths of Economists, American Economic Review Papers and Proceedings, vol.83, n², pp.52-56.

T. Lancaster (1990), The Econometric Analysis of Transition Data, Econometric Society Monographs, New York, Cambridge University Press.

Livre Blanc (2002), Les Femmes dans la Recherche Française, Ministère de la Recherche.

Long J., Allison P., R. McGinnis (1993), Rank Advancement in Academic Careers: Sex Differences and the Effects of Productivity, American Sociological Review, vol.58, n5, pp.703-722.

Mc Dowell J., Singell L., J. Ziliak (2001), Gender, Promotion in the Economic Profession, Industrial and Labor Relations Review, vol.54, n², pp.224-244.

Mixon F., Trevino L. (2005), Is there gender discrimination in named professorships? An Econometric analysis of economics departments in the US South, Applied Economics, vol. 37, pp.849-854.

Oaxaca R. (1973), Male-Female Wage Differentials in Urban Labor Markets, International Economic Review, vol.14, n³, pp.693-710.

Ransom M., S. Megdal (1993), Sex Differences in the Academic Labor Market in the Affirmative Action Era, Economics of Education Review, vol.12, n¹, pp.21-43.

Rapport ETAN (2000), Femmes et Sciences, Commission Européenne.

Schneider A. (1998), Why Don't Women Publish as Much as Men?, Chronicle of Higher Education, vol.45, $\mathrm{n}^{\circ}$, pp.14-16.

Spurr S., Sueyoshi G. (1994), Turnover and promotion of Lawyers: An Inquiry into Gender Differences, Journal of Human Resources, vol.29, n³, pp.813-842.

Ward M. (2001)a, The Gender Salary Gap in British Academia, Applied Economics, vol. 33, n¹3, pp. 1669-1681.

Ward M., (2001)b, Gender and Promotion in the Academic Profession, Scottish Journal of Political Economy, vol.48, n³, pp.283-302.

White H. (1982), "Maximum Likelihood Estimation of Misspecified Models", Econometrica, n53, pp.16.

Table 1: Proportion of researchers in senior positions

\begin{tabular}{|l|c|c|}
\hline & Men & Women \\
\hline INRA & $51 \%$ & $15 \%$ \\
\hline Universities & $43 \%$ & $18 \%$ \\
\hline Public research institutes & $45 \%$ & $25 \%$ \\
\hline
\end{tabular}

Source: Livre Blanc, 2002 


\section{Page 49 of 54}


Table 2: Descriptive statistics

\begin{tabular}{|c|c|c|c|c|c|c|c|}
\hline Variables & Full sample & Females & $\begin{array}{c}\text { Senior } \\
\text { Researchers }\end{array}$ & $\begin{array}{c}\text { Female } \\
\text { Researchers }\end{array}$ & $\begin{array}{c}\text { Male } \\
\text { Researchers }\end{array}$ & $\begin{array}{c}\text { Female Senior } \\
\text { Researchers }\end{array}$ & $\begin{array}{l}\text { Male Senior } \\
\text { Researchers }\end{array}$ \\
\hline PROM: being promoted to senior position & $40.9 \%$ & $22.0 \%$ & & & & & \\
\hline FEM: being female & $35.6 \%$ & & $19.2 \%$ & & & & \\
\hline COH1: hired before 1980 & $31.9 \%$ & $12.6 \%$ & $64.4 \%$ & $4.0 \%$ & $14.3 \%$ & $42.9 \%$ & $69.5 \%$ \\
\hline HDR: having the Ph.D. supervisor diploma & $14.3 \%$ & $15.7 \%$ & $17.1 \%$ & $6.1 \%$ & $17.9 \%$ & $50.0 \%$ & $9.3 \%$ \\
\hline TOP_UNIV: graduated from a top university & $27.7 \%$ & $18.9 \%$ & $45.2 \%$ & $17.2 \%$ & $14.3 \%$ & $25.0 \%$ & $50.0 \%$ \\
\hline POSTDOC: having held a postdoctoral fellowship & $10.4 \%$ & $14.2 \%$ & $3.4 \%$ & $17.2 \%$ & $13.4 \%$ & $3.6 \%$ & $3.4 \%$ \\
\hline MOB: mobility since entry at INRA & $17.4 \%$ & $13.4 \%$ & $18.5 \%$ & $14.1 \%$ & $18.8 \%$ & $10.7 \%$ & $20.3 \%$ \\
\hline PUB_SCORE: publication productivity & 22.66 & 23.62 & 15.65 & 19.93 & 34.22 & 36.67 & 10.66 \\
\hline NPROJECT: number of projects & 1.39 & 1.35 & 1.51 & 1.08 & 1.52 & 2.32 & 1.31 \\
\hline NPROJ_C: number of projects coordinated & 0.53 & 0.45 & 0.64 & 0.35 & 0.54 & 0.79 & 0.60 \\
\hline BOSS: managing team or laboratory & $15.1 \%$ & $7.1 \%$ & $30.8 \%$ & $3.0 \%$ & $5.4 \%$ & $21.4 \%$ & $33.1 \%$ \\
\hline COMMIT: participating in strategic committees & $62.5 \%$ & $69.3 \%$ & $58.9 \%$ & $67.7 \%$ & $62.5 \%$ & $75.0 \%$ & $55.1 \%$ \\
\hline NETW: having networking activities & $13.4 \%$ & $8.7 \%$ & $17.8 \%$ & $6.1 \%$ & $14.3 \%$ & $17.9 \%$ & $17.8 \%$ \\
\hline Number of observations & 327 & 127 & 146 & 99 & 112 & 28 & 118 \\
\hline
\end{tabular}


Figure 1: Kaplan-Meier hazard rates

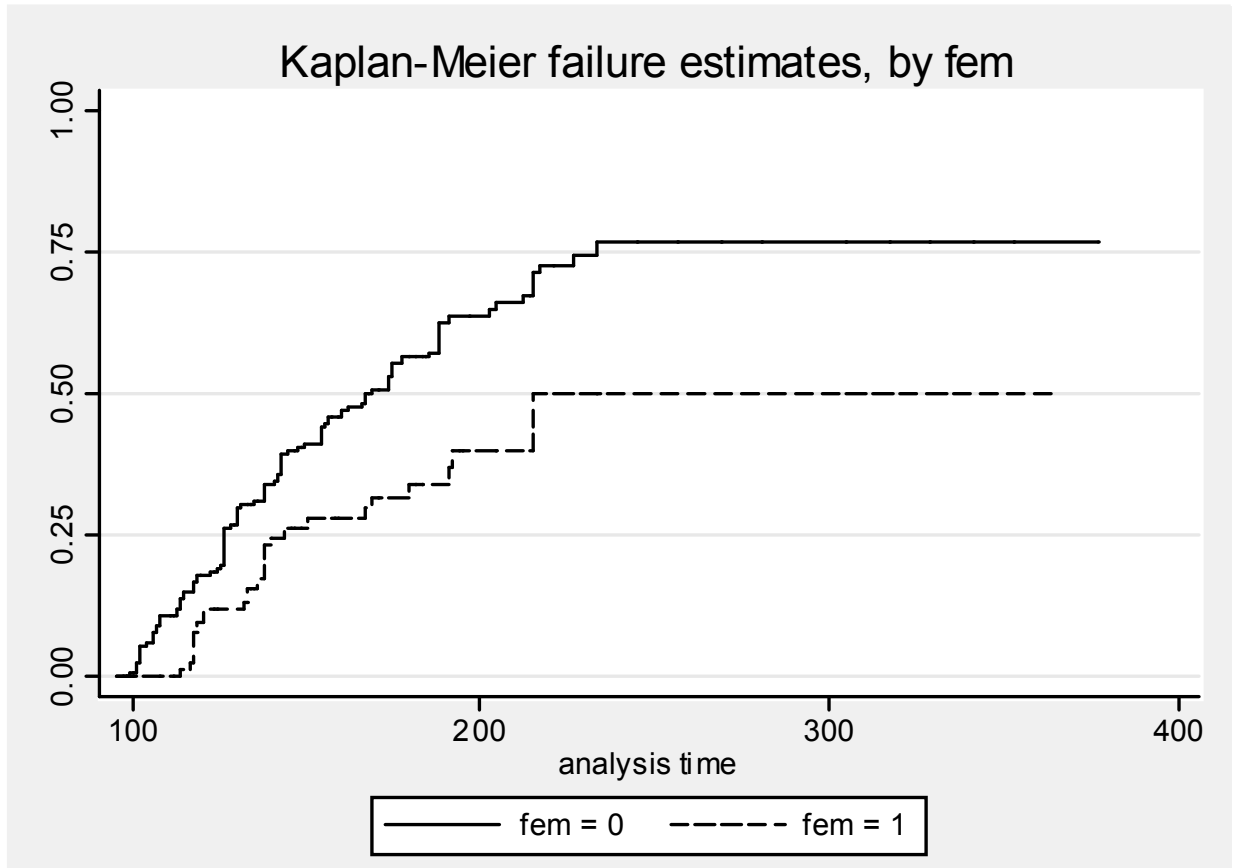


Table 3: The determinants of promotion duration

\begin{tabular}{|c|c|c|c|c|c|c|}
\hline \multirow{3}{*}{ Explanatory factors } & \multicolumn{2}{|c|}{ Model 1} & \multicolumn{2}{|c|}{ Model 2} & \multicolumn{2}{|c|}{ Model 3} \\
\hline & \multicolumn{2}{|c|}{ Full sample } & \multicolumn{2}{|c|}{ Male } & \multicolumn{2}{|c|}{ Female } \\
\hline & $\begin{array}{l}\text { Time } \\
\text { ratios }\end{array}$ & t-ratios & $\begin{array}{l}\text { Time } \\
\text { ratios }\end{array}$ & $t$-ratios & $\begin{array}{l}\text { Time } \\
\text { ratios }\end{array}$ & t-ratios \\
\hline Constant & 1.02 & $2.01^{* *}$ & 0.99 & $1.04^{n s}$ & 1.01 & $0.73^{n s}$ \\
\hline FEM: being female & 1.12 & $2.67^{* * *}$ & - & - & - & - \\
\hline COH1: hired before 1980 & 0.89 & $-3.11^{* * *}$ & 0.71 & $-3.96^{* * *}$ & 0.95 & $-3.01^{* * *}$ \\
\hline TOP_UNIV: graduated from a top university & 0.93 & $-1.87^{*}$ & 0.92 & $-2.15^{*}$ & 0.98 & $-1.65^{n S}$ \\
\hline HDR: having the Ph.D. supervisor diploma & 0.90 & $-2.12^{* *}$ & 0.98 & $-1.21^{n s}$ & 0.92 & $-2.28^{* *}$ \\
\hline POSTDOC: having held a postdoctoral fellowship & 1.01 & $-1.18^{n s}$ & 1.02 & $0.97^{n s}$ & 0.96 & $-2.19^{* *}$ \\
\hline MOB: mobility since entry at INRA & 0.95 & $-2.09^{* *}$ & 0.94 & $-2.08^{* *}$ & 0.98 & $-1.14^{n S}$ \\
\hline NPROJECT: number of projects & 0.87 & $-2.12^{\star *}$ & 0.88 & $-1.93^{*}$ & 0.95 & $-1.98^{* *}$ \\
\hline NPROJ_C: number of projects coordinated & 0.84 & $-3.73^{* \star *}$ & 0.76 & $-3.82^{* \star *}$ & 0.98 & $-1.54^{n S}$ \\
\hline PUB_SCORE: publication productivity & 0.97 & $-1.53^{n s}$ & 0.99 & $-1.54^{n S}$ & 0.56 & $-2.31^{\star \star \star}$ \\
\hline BOSS: managing team or laboratory & 0.81 & $-6.26^{* * *}$ & 0.63 & $-4.02^{* \star *}$ & 1.01 & $1.06^{n s}$ \\
\hline NETW: having networking activities & 0.97 & $-1.42^{n s}$ & 0.98 & $-1.07^{n s}$ & 0.96 & $-1.38^{n s}$ \\
\hline COMMIT: participating to strategic committees & 0.98 & $-0.61^{n s}$ & 0.97 & $-1.04^{n s}$ & 1.03 & $0.97^{n s}$ \\
\hline COH1 ${ }^{*}$ PUB_SCORE & 1.07 & $2.15^{* *}$ & 0.94 & $2.61^{* * *}$ & 1.04 & $1.13^{* * *}$ \\
\hline Sigma & 0.31 & $17.04^{\star * \star}$ & 0.23 & $7.41^{\star * *}$ & 0.18 & $5.59^{\star \star *}$ \\
\hline Theta & 1.53 & $3.88^{* \star \star}$ & 1.18 & $4.33^{* * *}$ & 1.79 & $4.06^{* * *}$ \\
\hline Log-Likelihood & & 3.52 & & 3.91 & & \\
\hline Observations & & & & & & \\
\hline
\end{tabular}

NB: Estimated coefficients have been rounded to two decimal places. Robust t-ratios (using heteroscedasticconsistent errors from White's (1982) procedure) are reported.

${ }^{* * *}$ : statistically significant at $1 \%$ level, ${ }^{* *}$ : significant at $5 \%$ level, ${ }^{*}$ : significant at $10 \%$ level, ns: not significant 
Figure 2: Predicted hazard rates by gender (model 1)

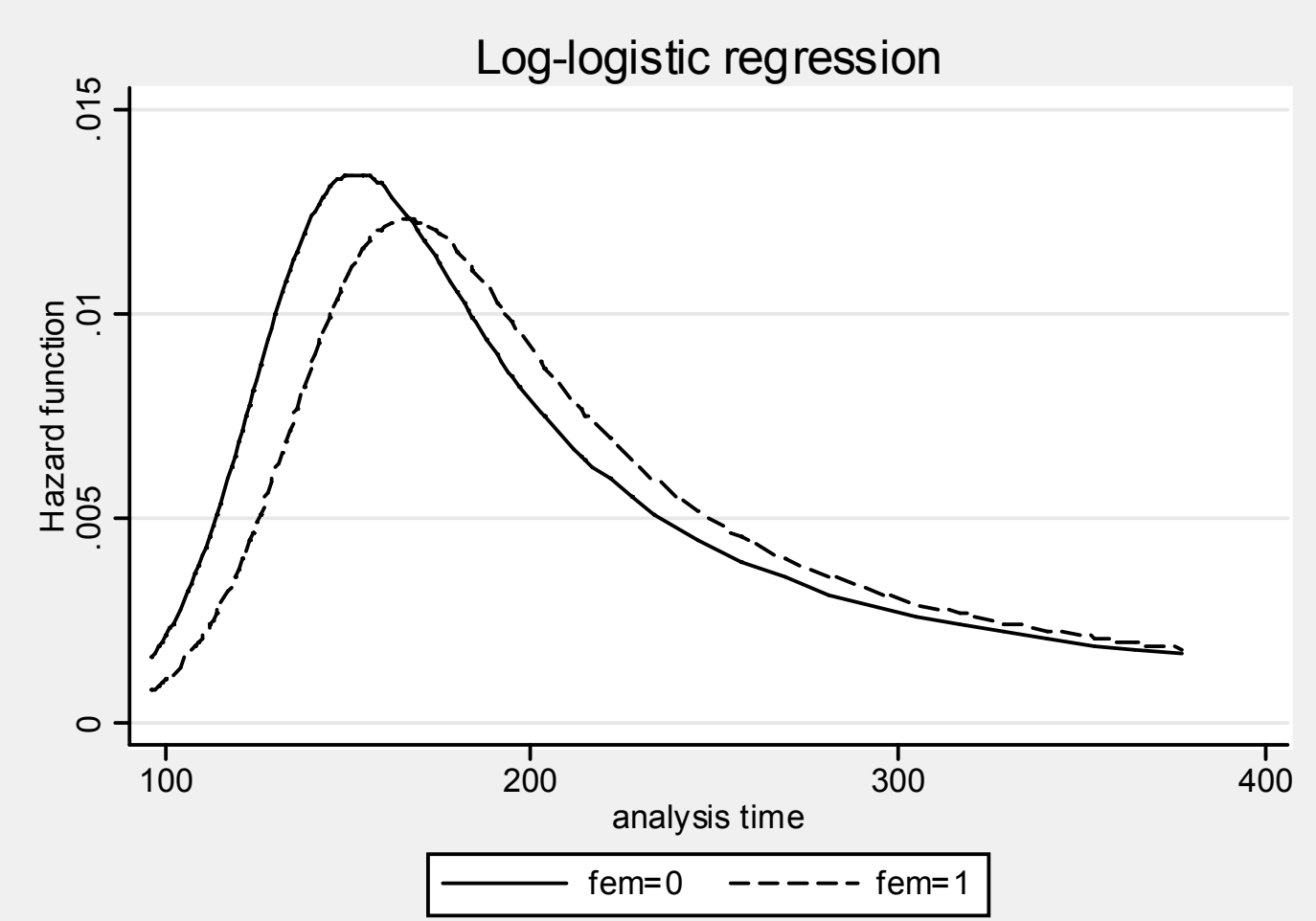


Table 4: Predicted and simulated median promotion durations

\begin{tabular}{|l|c|c|c|c|}
\hline \multirow{2}{*}{} & \multicolumn{2}{|c|}{ Predicted from model 1 } & \multicolumn{2}{c|}{ Simulated from models 3 and $4^{*}$} \\
\cline { 2 - 5 } & male & female & male & female \\
\hline Median duration & 192.18 & 225.26 & 225.04 & 236.23 \\
\hline
\end{tabular}

* These simulations were obtained using the mean values of $\mathrm{X}$ for females (males) but the estimated coefficients for males (females). 